\title{
Awareness and Practice of Standard Precaution for Infection Control among Student Nurses
}

\author{
Tatyannah Alexa E. Maristela ${ }^{1}$, Jemarjo Coleen R. Alano ${ }^{2}$, Winston T. Wushoma ${ }^{3}$ \\ Tedd Abiel L. Jumarang ${ }^{4}$ and Susy A. Jael ${ }^{5}$ \\ ${ }^{1,2,3,4}$ Student, Adventist University of the Philippines \\ ${ }^{5}$ Faculty, Adventist University of the Philippines \\ SAJael@aup.edu.ph
}

\begin{abstract}
Infection control is a critical concern in any health care setting among healthcare providers which include student nurses. The dearth of literature and studies among student nurses prompted the conduct of this study. This study sought to determine the awareness and practice of standard precaution (handwashing, safe handling of needles and other sharp devices, and disposal of contaminated materials) for infection control among student nurses. It also determined the relationship between awareness and practice on standard precaution for infection control, the difference in the practice of standard precaution for infection control when gender and year level were considered, and the predictors of practice of standard precaution for infection control. Data were collected from 121nursing students comprising of 2nd, 3rd and 4th years. Participants were obtained through purposive sampling, from one of the universities in the Philippines. Results showed that the awareness of the respondents was very high, practice of standard precautions for infection control in terms of handwashing and proper handling and disposal of contaminated materials were excellent, with very good practice in terms of safe handling of needles and other sharp devices. There was statistically significant relationship between awareness and practice on standard precaution in terms of proper handling and disposal of contaminated materials, wherein those with high awareness are more likely to have a better practice. However, there was no significant relationship between awareness and the practice of standard precautions for infection control in terms of handwashing and safe handling of needles and other sharp devices. Year level and gender did not make any significant difference in the practice of standard precaution for infection control. However, year level and gender were significant predictors of practice of standard precaution for infection control in terms of safe handling of needles and other sharp devices, wherein students in higher level tend to have a better practice. Awareness was a significant predictor of practice of standard precaution for infection control in terms of proper handling and disposal of contaminated materials, wherein the higher the awareness the better is the practice. Standard precaution for infection control concept and proper practice should be introduced to the students as early as their first year in the nursing program.
\end{abstract}

Keywords: Standard Precaution, Infection Control 


\section{INTRODUCTION}

Infection control must be observed by every nurse because non-compliance to the standard precaution is associated with the spread of infection. According to Samson-Akpan and Bassey (2012), one of the major causes of morbidity in the clinical area is nosocomial infection. Healthcare associated infections are grave problems in the healthcare sector that impose a great threat to patient's safety (Hammoud, Ghazi, Nassredine, \& Haidar, 2017). Nurses should have the proper knowledge and should practice according to standard precautions while giving care to patients as an initial level of infection control. Previous studies revealed that student nurses have poor practice of standard infection control although they have good knowledge about standard precaution of infection control (Barikani \& Afaghi, 2012). Studies have been done among staff nurses on practice and knowledge of standard precaution on infection control. However, there is dearth of literature and studies among nursing students.

The aim of the study was to determine the level of awareness and the extent of practice on standard precaution for infection control among nursing students, in terms of handwashing, safe handling of needles and other sharp devices, and proper handling and disposal of contaminated materials. Moreover, it determined the relationship between awareness and practice, the difference in the practice of standard precautions for infection control considering the year level and gender, and the predictors of practice of standard precaution for infection control

\section{LITERATURE REVIEW}

Awareness

Despite the developments in the health care system, the risk of having hospital-acquired infection still rises. Nursing personnel possess a high risk of acquiring disease from patients and has the possibility of transmitting infections to the patients. Having awareness about the standard precautions and practicing them has a vital role in preventing and acquiring infection or the risk of having hospital-acquired infection (Acharya, Khandekar, Sharna, Kataria, 2013; Vaman, et al., 2016). Solutions on the growing problem of healthcareassociated infections and their impact on the healthcare system have relied greatly on infection control policies that emphasized good hygiene. However, healthcare workers' must consistently follow these practices for the infection control strategies to be effective 
(Aboelela, Stone, \& Larson, 2012). Nurses who have high awareness in infection control tends to educate their patients and the family members about these practices more compared to the nurses with low awareness (Hammoud et al., 2017).

Iliyasu et al., (2016), argued that poor knowledge on the risk of transmission of blood borne pathogens would mean the underestimation of the risk of transmission. This condition may put healthcare workers at risk of being infected with this blood borne pathogens after exposure. Awareness is essential in health care and delivery system and helps the medical staff deliver care more effectively.

Practice of Standard Precaution for infection Control

Standard precautions are a set of protocols for infection control practices. This set of protocols is used to prevent transmitting diseases that can be acquired by contact with nonintact skin and mucous membranes, with blood and body fluids. Even if the client or equipment/ materials seem not infectious these infection control practices standards are needed to be applied in providing care to every individual (Wisconsin Department of Health Services, 2018).

Hamadah et al. (2015) argued that the compliance of all the healthcare workers to the universal standards on precautions for infection control is an effective tool in controlling and also in preventing the occurrence of hospital-acquired infections. Following these control precautions does not only protect the patients but also the healthcare workers. It is essential to implement these processes and procedures to safeguard the patient, care provider and the facility itself.

Infections developed in the hospital or healthcare facilities can affect people of any age. These infections can worsen the existing or underlying health conditions of the client, can delay their recovery and can affect the quality of life. Healthcare-associated infections can occur not only among sick clients but even among healthy individuals. More so healthcare workers and family members are also at risk of acquiring health care- associated infections when caring for people. High standard of infection prevention and consistent practice and with clean environment can help reduce the risk of healthcare associated infections (Mehta et al., 2014). 
There are three indicators of practice of standard precautions for infection control that are included in this study namely: (a) hand washing, (b) safe handling of needles and other sharp devices, and (c) proper handling and disposal of contaminated materials.

Hand washing.

According to Hamadah et al. (2015), hand washing is the most essential precautionary tool in reduction of nosocomial healthcare associated infections. Also, Wisconsin Department of Health Services (2018) stated that hand washing should be performed before and after every interaction and process done in the facility. Hand washing should be performed every time there is a contact with the client, immediately after touching body fluids and blood, contact with contaminated items, immediately after removing gloves, when moving from contaminated body sites to clean body sites during client care, after touching objects and medical equipment in the immediate client-care vicinity.

Importance of proper hand hygiene must be given emphasis in the health-related curricula and healthcare facilities because improper hand washing may lead to patient's morbidity and mortality. The higher and the wider the level of knowledge and awareness the nurses have regarding hand washing standards, the more precautions will be observed, and the greater will be the reduction in health associated infection rates (Hamadah et al., 2015).

Safe handling of needles and other sharp devices.

To inhibit the health care worker from being exposed to blood borne pathogens, safe handling of needles and other sharp devices are being implemented (Wisconsin Department of Health Services, 2018). The Needle stick Safety and Prevention Act ordered the use of sharp items with engineered safety devices if the suitable devices exist and a vailable. Due to the outbreaks of hepatitis B and hepatitis C infections healthcare facilities re-emphasize safe injection practices. All healthcare personnel who give injections should strictly follow the Center for Disease Control and Prevention (CDCP) recommendations - whenever a medication vial or IV bag is being retrieved, new needles and syringe should be used, every injection to a client new needles and syringe should also be used, it should only be one client 
when using medication vials as much as possible and safe injection practices packet (CDCP, 2017).

Sharps must be in a container that is rigid, puncture resistant, closable, and leak proof with a label that says sharps and with the biohazard symbol. Sharps must be carefully used with extreme caution. It is highly not encouraged to clip, break, and recap the needles. Containers for sharps should not be filled more than $2 / 3$ full. If the container is filled with sharps, it must be closed securely, and must be destroyed medical waste by incineration (Hraishawi \& Naji, 2015).

\section{Proper handling and disposal of contaminated materials.}

The World Health Organization (2018), defined infectious waste as a contaminated waste if these include blood, infectious agents, waste from patients who were isolated, diagnostic samples that were discarded because they contain blood and body fluids and other materials that are contaminated such as swabs and bandages, and equipment like disposable medical devices.

According to Burton (2017), items that can be a threat to cleaners and people who are handling waste disposal includes syringes and needles, scalpel blades, bandages, bedding, soiled clothing and sanitary waste products. When a personnel is working in an environment with high risks like a healthcare setting, he/she should consider, act and think that everything that's being deal with is infectious. According to World Health Organization (2018), generally, $85 \%$ of waste that are in charge by health care settings is non-hazardous waste. But $15 \%$ of the waste is possibly infectious. This small part of waste could have organisms which are harmful and it may affect other patients, staff and general public by being infected.

\section{METHODS}

The study utilized a quantitative descriptive-evaluative, descriptive-comparative, and descriptive-correlational research design.

\section{Population and Sampling}

Data were collected from 121 nursing students who were in their second, third and fourth years, selected through purposive sampling, from one nursing school in Cavite, Philippines. 
Out of the 121, 49 were males and 72 were females; 39 were in their second year, 39 were in their third year, and 43 were in their fourth year. Those who had clinical experience or practice aside from what is required in the nursing curriculum were excluded from the study.

\section{Instrumentation}

The survey questionnaire includes three (3) parts. The first part is the demographic profile of the respondents such as year level and gender. The second part was questions on awareness on standard precaution for infection control, adapted from the study of Samson-Akpan and Bassey (2012). Some items were modified on the basis of relatability to the target population and related literature. Five-point Likert scale (strongly disagree, disagree, neither agree not disagree, agree and strongly agree) was used as a measure for each item. Third part were questions to evaluate the practice of standard precaution for infection control that includes handwashing, safe handling of needles and other sharp devices, and proper handling and disposal of contaminated materials, adapted from the study of Tufail, Afzal, Perveen, Waqas, and Gilani (2017), with some items modified to fit the respondents and related literature. The items were measured using the Five-point Likert scale (never, rarely, sometimes, most of the time, and always). The survey questionnaire had undergone reliability test and content validation from five experts who were nurse educators and clinical practitioners who holds masters and doctorate degrees in nursing.

\section{Analysis of Data}

This study used the Statistical Package for Social Sciences (SPSS) version 22. Descriptive statistics such as frequency, percentage, mean, and standard deviation were used to describe the demographic profiles of the respondents, the level of awareness, and the extent of practice. Pearson Product Moment Correlation was used to determine the relationship between awareness and practice of standard precaution for infection control. Analysis of variance was used to determine the difference in the practice when gender and year level were considered. Further, linear regression was used to determine the predictors of practice of standard precaution for infection control.

\section{Ethical Consideration}


Approval was secured from the institution where the study was conducted and from the institution's Ethics Review Committee. The students were given a complete and detailed explanation about the nature and the purpose of the study. It was emphasized that participation was voluntary, and that participation in the study would have no influence on either their coursework grade or clinical hours requirement. An informed verbal consent was secured and all data sheets were kept confidential and anonymous.

\section{RESULTS}

Level of Awareness on Standard Precaution for Infection Control

Table 1 showed that awareness had an overall mean score of $4.80(\mathrm{SD}=.45)$, which is interpreted as very high.

Table 1. Level of Awareness of the Respondents

\begin{tabular}{lcccc}
\hline & Mean & SD & $\begin{array}{l}\text { Qualitative } \\
\text { Descriptor }\end{array}$ \\
\hline $\begin{array}{l}\text { Used needles and sharps should be disposed in sharp } \\
\text { containers. }\end{array}$ & 4.84 & .59 & Very High \\
$\begin{array}{l}\text { Disinfection of instruments should be done after each } \\
\text { contact with patients. }\end{array}$ & 4.80 & .57 & Very High \\
Glove should be used to handle contaminated materials. & 4.83 & .57 & Very High \\
Needle injuries should be reported to authority. & 4.70 & .65 & Very High \\
Hands should be washed before and after procedures. & 4.88 & .45 & Very High \\
Hands should be washed before and after each patient care. & 4.86 & .46 & Very High \\
Precautionary measure prevent HIV/AIDS and Hepatitis B & 4.69 & .62 & Very High \\
Awareness & $\mathbf{4 . 8 0}$ & $\mathbf{. 4 5}$ & Very High \\
\hline
\end{tabular}

Legend; $1.00-1.49=$ very low, $1.50-2.49=$ low, $2.50-3.49=$ fair, 3.50-4.49 = high, 4.50-5.00 $=$ very high

Extent of Practice on Standard Precautions for Infection Control of Student Nurses in terms of Handwashing

Table 2 revealed that the practice on standard precautions for infection control in terms of handwashing has an overall mean score of $4.54(S D=.45)$, which is interpreted as excellent.

Table 2. Extent of Practice on Standard Precautions for Infection Control in Terms of Handwashing of the Respondents 


\begin{tabular}{|c|c|c|c|}
\hline & Mean & SD & $\begin{array}{l}\text { Qualitative } \\
\text { Descriptor }\end{array}$ \\
\hline $\begin{array}{l}\text { I wash my hands before and after each } \\
\text { procedure for } 1 \text { minute. } \bigotimes\end{array}$ & 4.29 & .82 & Very Good \\
\hline $\begin{array}{l}\text { I wash my hands with soap under } \\
\text { running water. }\end{array}$ & 4.64 & .72 & Excellent \\
\hline $\begin{array}{l}\text { I wash hands before and after donning } \\
\text { of gloves. } \bigotimes\end{array}$ & 4.60 & .69 & Excellent \\
\hline $\begin{array}{l}\text { I wash my hands above the elbow. } \\
\text { I wash my hands before and after } \\
\text { invasive procedures. } \bigotimes\end{array}$ & $\begin{array}{l}3.93 \\
4.87\end{array}$ & $\begin{array}{r}1.08 \\
.39\end{array}$ & $\begin{array}{l}\text { Very Good } \\
\text { Excellent }\end{array}$ \\
\hline $\begin{array}{l}\text { I wash my hands after touching } \\
\text { patient's surroundings. }\end{array}$ & 4.57 & .72 & Excellent \\
\hline $\begin{array}{l}\text { I wash my hands when I come in } \\
\text { contact with patient's blood, bloody } \\
\text { fluid and secretion. }\end{array}$ & 4.91 & .29 & Excellent \\
\hline Handwashing & 4.54 & .45 & Excellent \\
\hline
\end{tabular}

Extent of Practice on Standard Precautions for Infection Control of Student Nurses in Terms of Safe Handling of Needles and Other Sharp Devices

Table 3 showed that the practice on standard precautions for infection control in terms of safe handling of needles and other sharp devices has an overall mean score of 3.91 ( $S D=$ .56), which is interpreted as very good. Using new needle with each injection of a client got the highest score which is $4.89(S D=.35)$, which is interpreted as excellent while the lowest score is recapping needles before disposing them which is only $1.63(S D=1.15)$ and interpreted as fair.

Table 3. Extent of Practice on Standard Precautions for Infection Control in Terms of Safe Handling of Needles and Other Sharp Devices of the Respondents

\begin{tabular}{|c|c|c|c|}
\hline & Mean & SD & $\begin{array}{l}\text { Qualitative } \\
\text { Descriptor }\end{array}$ \\
\hline $\begin{array}{l}\text { I use separate syringe for aspirating } \\
\text { different vials. }\end{array}$ & 4.80 & .52 & Excellent \\
\hline I recap needles before disposing them. & 1.63 & 1.15 & Fair \\
\hline $\begin{array}{l}\text { I use new needle with each injection of } \\
\text { a client. }\end{array}$ & 4.89 & .35 & Excellent \\
\hline I reuse syringes for the same client. & 3.98 & 1.50 & Very Good \\
\hline I use the same needle for aspirating & 3.76 & 1.61 & Very Good \\
\hline
\end{tabular}


different vials.

$\begin{array}{llll}\text { I use separate needle for aspirating } & 4.39 & 1.15 & \text { Very Good }\end{array}$ different vials.

Sharps

$\begin{array}{lll}3.91 & .56 & \text { Very Good }\end{array}$

Legend; $1.00-1.49=$ poor, $1.50-2.49=$ fair, $2.50-3.49=$ good, $3.50-4.49=$ very good, 4.50 -

$5.00=$ excellent

Extent of Practice on Standard Precautions for Infection Control of Student Nurses in Terms of Proper Handling and Disposal of Contaminated Materials

Table 4 showed that the practice on standard precautions for infection control in terms of proper handling and disposal of contaminated materials is excellent, with an overall mean score of $4.85(S D=.32)$.

Table 4. Extent of Practice on Standard Precautions for Infection Control in Terms of Proper Handling and Disposal of Contaminated Materials of the Respondents

\begin{tabular}{llll}
\hline & Mean & $\boldsymbol{S D}$ & $\begin{array}{l}\text { Qualitative } \\
\text { Descriptor }\end{array}$ \\
\hline $\begin{array}{l}\text { I wear gloves when handling soiled linens and clothing. } \\
\text { I dispose the following in a designated bin for infectious waste material: }\end{array}$ & 4.70 & .67 & Excellent \\
a. Used dressing & 4.94 & .23 & Excellent \\
b. Used gloves & 4.93 & .28 & Excellent \\
c. Used mask & 4.87 & .46 & Excellent \\
d. Used needles & 4.78 & .83 & Excellent \\
d. Used syringe & 4.88 & .55 & Excellent \\
Disposal & $\mathbf{4 . 8 5}$ & $\mathbf{. 3 2}$ & Excellent
\end{tabular}

Legend; $1.00-1.49=$ poor, $1.50-2.49=$ fair, $2.50-3.49=$ good, $3.50-4.49=$ very good, 4.50 $5.00=$ excellent

Relationship between Awareness and Practice on Standard Precautions for Infection Control Table 5 revealed that there is no significant relationship between awareness and practice on standard precaution for infection control among student nurses in terms of handwashing and safe handling of needles and other sharp devices. However, there is a significant relationship $(r=.183, p=.044)$ between awareness and practice on standard precaution for infection control among student nurses in terms of proper handling and disposal of contaminated materials.

Table 5. Relationship between Awareness and Practice on Standard Precautions for Infection Control 


\begin{tabular}{lccl}
\hline & Awareness & & $\begin{array}{l}\text { Qualitative } \\
\text { Descriptor }\end{array}$ \\
\hline Handwashing & .144 & $\boldsymbol{p}$ & Not Significant \\
Sharps & .024 & .115 & Not Significant \\
Disposal & .183 & .796 & Significant \\
\hline Significant at $p \leq .05$ & & .044 &
\end{tabular}

Difference in the practice of Standard Precaution for Infection Control when Year Level is Considered

Table 6 showed that there is no significant difference in the practice of standard precaution for infection control among student nurses when year level was considered. However there is a slight difference in the mean of the practice of proper handling and disposal of contaminated materials between the third year and second year level but it is not statistically significant. Although it is not statistically significant it shows that the mean in practice is higher in third and fourth year when compared to second year.

Table 6. Difference in the practice of Standard Precaution for Infection Control when Year Level was Considered

\begin{tabular}{llllccc}
\hline \multicolumn{1}{c}{ Practices } & Level & $\mathbf{M}$ & $\boldsymbol{S D}$ & $\boldsymbol{F}$ & $\boldsymbol{p}$ & $\begin{array}{l}\text { Qualitative } \\
\text { Descriptor }\end{array}$ \\
\hline Handwashing & $2^{\text {nd }}$ & 4.61 & .42 & 1.881 & .157 & Not Significant \\
& $3^{\text {rd }}$ & 4.43 & .54 & & & Not Significant \\
\multirow{3}{*}{ Sharps } & $4^{\text {th }}$ & 4.58 & .37 & & & Not Significant \\
& $2^{\text {nd }}$ & 3.77 & .65 & 2.106 & .126 & Not Significant \\
Disposal & $3^{\text {rd }}$ & 3.91 & .51 & & & Not Significant \\
& $4^{\text {th }}$ & 4.02 & .51 & & & Not Significant \\
& $2^{\text {nd }}$ & 4.84 & .35 & .325 & .723 & Not Significant \\
& $3^{\text {rd }}$ & 4.88 & .25 & & & Not Significant \\
& $4^{\text {th }}$ & 4.83 & .35 & & & Not Significant \\
\hline
\end{tabular}

Significant at $p \leq .05$

Difference in the practice of Standard Precaution for Infection Control when Gender is Considered

Table 7 presents the difference in the handwashing $t(119)=1.245, p=.215$, safe handling of needles $t(119)=-1.499, p=.136$ and other sharp devices and proper handling and disposal of contaminated materials $t(119)=.456, p=.649$ when gender is considered. There is no significant difference in the practice of standard precaution for infection control among student nurses when gender was considered. 
Table 7. Difference in the Practice of Standard Precaution for Infection Control when Gender was Considered

\begin{tabular}{llllccc}
\hline \multicolumn{1}{c}{ Practices } & Gender & $\boldsymbol{M}$ & SD & $\boldsymbol{t}(\mathbf{1 1 9 )}$ & $\boldsymbol{p}$ & $\begin{array}{l}\text { Qualitative } \\
\text { Descriptor }\end{array}$ \\
\hline \multirow{2}{*}{ Handwashing } & Male & 4.60 & .42 & 1.245 & .215 & Not Significant \\
\multirow{2}{*}{ Sharps } & Female & 4.50 & .47 & & & Not Significant \\
& Male & 3.81 & .58 & 1.499 & .136 & Not Significant \\
& Female & 3.97 & .55 & & & Not Significant \\
Disposal & Male & 4.87 & .29 & .456 & .649 & Not Significant \\
& Female & 4.84 & .34 & & & Not Significant \\
\hline
\end{tabular}

Significant at $p \leq .05$

Predictors for Practice of Standard Precaution for Infection Control in Handwashing, Safe Handling of Needles and other Sharp Devices, Proper Handling and Disposal of Contaminated Materials

Predictor for Handwashing

Among the variables (Awareness, Year Level, Gender) there is no predictor of standard precaution for infection control in terms of handwashing.

Predictor for Safe Handling of Needles and other Sharp Devices

Table 8. Predictors on Practice of Standard Precaution for Infection Control (Safe Handling of Needles and other Sharp Devices)

\begin{tabular}{|c|c|c|c|c|c|c|}
\hline \multirow{2}{*}{ Predictors } & \multirow{2}{*}{$R^{2}$ Change } & \multirow{2}{*}{$\begin{array}{r}\mathrm{UC} \\
B\end{array}$} & \multicolumn{2}{|r|}{ SC } & \multirow[b]{2}{*}{$t$} & \multirow[b]{2}{*}{$p$} \\
\hline & & & $S E$ & $\beta$ & & \\
\hline (Constant) & & 3.24 & .24 & & 13.67 & .000 \\
\hline Year Level & .034 & 0.16 & .06 & .229 & 2.51 & .013 \\
\hline Gender & .034 & 0.22 & .11 & .190 & 2.08 & .040 \\
\hline \multicolumn{7}{|c|}{$R=.261, R^{2}=.068, F=4.33, p=.015$} \\
\hline
\end{tabular}


Year level and gender entered as significant predictors of safe handling of needles and other sharp devices $(R=.261, F=4.33, p=.015)$. Together they explain $6.8 \%$ of the variance in practices on needles and sharps, of which $3.4 \%$ can be explained by each variable.

The prediction of equation for practice on safe handling of needles and other sharp devices is Practice on Needles and Sharps $=3.24+.16$ Year Level +.22 Gender

Predictor for Proper Handling and Disposal of Contaminated Materials

Table 9. Predictors on Practice of Standard Precaution for Infection Control (Proper Handling and Disposal of Contaminated Materials)

\begin{tabular}{|c|c|c|c|c|c|c|}
\hline \multirow{2}{*}{ Predictors } & \multirow{2}{*}{$\begin{array}{c}R^{2} \\
\text { Change }\end{array}$} & \multirow{2}{*}{$\begin{array}{r}\mathbf{U C} \\
B\end{array}$} & \multicolumn{3}{|c|}{ SC } & \multirow[b]{2}{*}{$p$} \\
\hline & & & $S E$ & $\beta$ & $t$ & \\
\hline (Constant) & & 4.23 & .31 & & 13.69 & .000 \\
\hline Awareness & .034 & .13 & .06 & .183 & 2.03 & .044 \\
\hline
\end{tabular}

Significant at $p \leq .05$

Awareness entered as significant predictor of proper handling and disposal of contaminated materials $(R=.183, F=4.126, p=.044)$.

The prediction of equation for practice on proper handling and disposal of contaminated materials is Practice on Proper Handling and Disposal of Contaminated Materials = $4.23+.13$ Awareness

\section{DISCUSSION}

The result revealed that nursing students are very much aware about the standard precaution for infection control. This may be due to the fact that the respondents were already exposed to clinical practice with concepts learned in class. According to Hammoud et al., (2017), nurses who have high awareness in infection control tend to educate their patients and the family members about these practices more compared to the nurses with low awareness. In addition, Iliyasu et al., (2016) metioned that, poor knowledge on the risk of transmission of blood borne pathogens will lead to increased risk of transmission, which may put health care workers at risk of being infected with these pathogens following exposure. 
Further, result indicated that the respondents had an excellent handwashing practice in the clinical area. This might be probably because the students were already very much aware of the standard precautions for infection control because of the knowledge gained in class and in the clinical area. Hand washing is considered very important and one of the most effective and economical method to prevent infection. Thus it is necessary for the nurses and the patients to wash hands to prevent the spread of microorganisms.

Result also revealed that, the respondents had a very good practice in terms of safe handling of needles and other sharp devices. The knowledge gained by the students in the classrooms may have contributed to their very good practice. All healthcare personnel who give injections should strictly follow to the CDCP recommendations - safe injection practices, which include the following; use of a new needle and syringe every time a medication vial or IV bag is accessed, use of new needle and syringe with each injection of a client, and used medication vials for one client only (CDCP, 2017).

Moreover, the respondents had excellent practice on standard precaution for infection control in term of proper handling and disposal of contaminated materials. This might be probably due to the knowledge they have gained in class.

The result also revealed that there is no significant relationship between awareness and practice on standard precaution for infection control among student nurses in terms of handwashing and safe handling of needles and other sharp devices. However, there is a significant relationship between awareness and practice on standard precaution for infection control among student nurses in terms of proper handling and disposal of contaminated materials, which indicates that the higher the awareness level the better is the practice. Having the knowledge and awareness about standard precautions and practicing them has a vital role on preventing and acquiring infections (Acharya et al., 2013). Lee, Park, and Jo (2017) study on awareness and performance of standard precaution guidelines designed to prevent medical-related infections, showed that awareness on infection control had a positive correlation with a performance of standard precautions.

Hamadah et al., (2015) study, confirmed that the compliance of all the healthcare workers to the universally agreed standards on infection control precautions is an effective tool in controlling and preventing the possibility of the occurrence of hospital-acquired infections. 
Following these control precautions does not only protect the patients but also the healthcare workers.

The result indicated that the practice of handwashing, proper handling and disposal of contaminated materials and safe handling and disposing of contaminated materials are the same among the nursing students who were in their second, third and fourth year level. In contrast, the study done by Yang, (2012) student nurses who is in higher level with standard precautions training had greater precaution compliance than those who are in lower level and doesn't have enough standard precautions exposure.

Year level and gender were predictors of practices on safe handling of needles and other sharp devices. Year level positively influences practice on safe handling of needles and other sharp devices, which implies that students in higher year level tend to have better practice. Further, female tend to have better practices than male. Suliman (2018), concurred that higher education can make the difference in patient safety in many situations. Their study show that nursing students in their fourth year had better knowledge scores than students in their second year. This may be related to the fact that nurses in their fourth year had undergone more courses, more concepts and more experience in infection control practices than those in the lower years.

Moreover, awareness is a predictor of proper handling and disposal of contaminated materials. Awareness positively influence practice on handling and disposal, which implies that those with high awareness are more likely to have better handling and disposal practices. According to Mathur, Dwivedi, and Misra (2012), education is a critical element in the training of all health care workers. Emphasis should be given in training regarding biomedical waste management that will make an impact on practices of appropriate waste disposal. Furthermore, according to Mathur et al. (2011), adequate knowledge about the health hazard of hospital waste, proper technique and methods of handling the waste, and practice of safety measures would be a great help to protect the healthcare workers and community from various adverse effects of the hazardous waste.

\section{Conclusion}

The study concluded that nursing students are aware and practices the standard precaution for infection control in terms of handwashing, proper handling and disposal of contaminated materials, and safe handling of needles and other sharp devices. The higher the awareness of 
the students, the better is the practice on standard precaution in terms of proper handling and disposal of contaminated materials. The higher the level in nursing program, the better is the practice on safe handling of needles and other sharp devices. Females tend to have better practice on safe handling of needles and other sharp devices.

Other variables such as years of clinical practice, clinical area, and clinical exposure maybe explored in future studies in different nursing schools, among the registered nurses in the clinical area, with different demographic profiles, using a larger sample size. The tool used may not have been sufficient to measure the actual awareness and practice variables, because it is totally dependent on the honesty of the respondents in answering the questions, thus another tool can be used in future investigations. Moreover, qualitative study can be done to gain a deeper understanding of the phenomenon and to explore what are other factors that would contribute to better practice of infection control.

\section{REFERENCES}

Aboelela, S., Stone, P., \& Larson, E. (2012). Effectiveness of bundled behavioural interventions to control healthcare-associated infections: a systematic review of the literature. The Hospital Infection Society, 101-108.

Acharya, A., Khandekar, J., Sharma, A., H., T., \& Kataria, A. (2013). Awareness and practices of standard precautions for infection control among nurses in a tertiary care hospital. Nursing Journal India, 104(6),275-279.

Barikani, A., \& Afaghi, A. (2012). Knowledge, Attitude and Practice towards Standard Isolation Precautions among Iranian Medical Students. Global Journal of Health Science, 4(2), 142-146.

Burton, L. (2017). What Methods Can Be Used for the Disposal of Infectious Waste?. Retrieved from https://www.highspeedtraining.co.uk/hub/disposal-of-infectiouswaste/

Centers for Disease Control and Prevention . (2017). Centers for Disease Control and Prevention . Retrieved from https://www.cdc.gov/handwashing/when-howhandwashing.html

Hamadah, R., Kharraz, R., Alshanqity, A., AlFawaz, D., Eshaq, A., \& Abu-Zaid, A. (2015). Hand Hygiene: Knowledge and Attitudes of Fourth-Year Clerkship Medical Students at Alfaisal University, College of Medicine, Riyadh, Saudi Arabia. Cureus. 310 
Hammoud, S., Ghazi, B., Nassredine, M., \& Haidar, M. (2017). Nurses' Awareness of Infection Control Measures, and the Role and Effect in Patient and Family Education. European Scientific Journal, 13(27). 59-76. doi: 10.19044/esj.2017.v13n27p59

Hraishawi, T., \& Naji, A. (2015, August ). Impact of Nurses' Knowledge Upon The Infection Control in Primary Health Care Centers at AL-Amara City. Kufa Journal For Nursing Science.

Iliyasu, G., Dayyab, F., Habib, Z., Tiamiyu, A., Abubakar, S., Mijinyawa, M., \& Habib, A. (2016). Knowledge and practices of infection control among healthcare workers in a Tertiary Referral Center in North-Western Nigeria. Annals of African Medicine, 15(1), 34-40.

Lee, S. J., Park, J. Y., \& Jo, N. (2017). Influence of Knowledge and Awareness on Nursing Students' Performance of Standard Infection Control Guidelines. Journal of Korean Academy of Nurisng Administration. 23(4):347-358.

Mathur, V. D. (2012, April). Knowledge, Attitude, and Practice about Biomedical Waste Management among Healthcare Personnel: A cross-sectional study. Indian J Community Med , 36(2), 1453-145.

Mehta, Y., Gupta, A., Todi, S., Myatra, S., Samaddar, D., Patil, V., \& Ramasubban, S. (2014, March). Guidelines for prevention of hospital acquired infections. Indian Journal of Critical Care Medicine , 18(3), 149-163.

Samson-Akpan, P., \& Bassey, P. (2012 ). Knowledge-Based and Practice of Infection Control Among Nurses In Immanuel General Hospital, Eket, Akwa Ibom State. West African Journal of Nursing . 26. 65-81.

Suliman, M. Q. (2018). Students Nurses knowledge and prevalence of Needle Stick Injury in Jordan. Nurse Education Today, 23-27.

Tufail, S., Afzal, M., Perveen, K., Waqas, A., \& Gilani, S. (2017). Knowledge, Attitude and Practice towards standard isolation precautions among registered Nurses. Saudi Journal of Medical and Pharmaceutical Sciences, 3(6A), 534-544.

Vaman, K., Papanna, M., Mohanty, U., Ranjan, R., Neelima, V., Kumar, N., . . . Unnikrishnan, B. (2016, August). Awareness of medical students in a medical college in Mangalore, Karnataka, India concerning infection prevention practices. Journal of Infection and Public Health, 6(4), 261-268.

Wisconsin Department of Health Services. (2018). Infection Control and Prevention Standard Precautions. Retrieved from https://www.dhs.wisconsin.gov/ic/precautions .htm 
Maristela, Alano, Wushoma, Jumarang \& Jael, Awareness and Practice of Standard Precaution ...

World Health Organization. (2018). World Health Organization. Retrieved from https://www.who.int/mediacentre/factsheets/fs253/en/

Yang L., G.-P. H.-W. (2014, December). Factors impacting compliance with standard precaution in nursing, China. International Journal of Infectious Diseases , 14(12), e1106-e1114. 